OPEN ACCESS

Edited by:

Jana Seifert,

University of Hohenheim, Germany

Reviewed by:

Amal Awad,

Mansoura University, Egypt

Veronica Maria Jarocki,

University of Technology Sydney,

Australia

${ }^{*}$ Correspondence:

Sara Soto

sara.soto@isglobal.org

Specialty section:

This article was submitted to Infectious Agents and Disease,

a section of the journal

Frontiers in Microbiology

Received: 28 October 2021 Accepted: 09 December 2021

Published: 11 January 2022

Citation:

Ballén V, Gabasa Y, Ratia C,

Sánchez M and Soto S (2022) Correlation Between Antimicrobial Resistance, Virulence Determinants and Biofilm Formation Ability Among Extraintestinal Pathogenic Escherichia coli Strains Isolated in Catalonia,

Spain. Front. Microbiol. 12:803862. do: 10.3389/fmicb.2021.803862

\section{Correlation Between Antimicrobial Resistance, Virulence Determinants and Biofilm Formation Ability Among Extraintestinal Pathogenic Escherichia coli Strains Isolated in Catalonia, Spain}

\author{
Victoria Ballén, Yaiza Gabasa, Carlos Ratia, Melany Sánchez and Sara Soto* \\ ISGlobal, Hospital Clínic-Universitat de Barcelona, Barcelona, Spain
}

Escherichia coli is a well-characterized bacterium highly prevalent in the human intestinal tract and the cause of many important infections. The aim of this study was to characterize 376 extraintestinal pathogenic $E$. coli strains collected from four hospitals in Catalonia (Spain) between 2016 and 2017 in terms of antimicrobial resistance, siderophore production, phylogroup classification, and the presence of selected virulence and antimicrobial resistance genes. In addition, the association between these characteristics and the ability to form biofilms was also analyzed. The strains studied were classified into four groups according to their biofilm formation ability: non-biofilm formers (15.7\%), weak (23.1\%), moderate (35.6\%), and strong biofilm formers (25.6\%). The strains were highly resistant to ciprofloxacin (48.7\%), trimethoprimsulfamethoxazole (47.9\%), and ampicillin (38\%), showing a correlation between higher resistance to ciprofloxacin and lower biofilm production. Seventy-three strains (19.4\%) were ESBL-producers. However, no relationship between the presence of ESBL and biofilm formation was found. The virulence factor genes fimH (92\%), pgaA (84.6\%), and irp1 $(77.1 \%)$ were the most prevalent in all the studied strains. A statistically significant correlation was found between biofilm formation and the presence of iro $N$, papA, fimH, sfa, cnf, hlyA, iutA, and colibactin-encoding genes $c / b A, c / b B, c l b N$, and $\mathrm{clbQ}$. Interestingly, a high prevalence of colibactin-encoding genes (19.9\%) was observed. Colibactin is a virulence factor, which interferes with the eukaryotic cell cycle and has been associated with colorectal cancer in humans. Most colibactin-encoding E. coli isolates belonged to phylogroup B2, exhibited low antimicrobial resistance but moderate or high biofilm-forming ability, and were significantly associated with most of the virulence factor genes tested. Additionally, the analysis of their clonal relatedness by PFGE showed 48 different clusters, indicating a high clonal diversity among the colibactin-positive strains. Several studies have correlated the pathogenicity of $E$. coli and the presence of virulence factor genes; however, colibactin and its relationship 
to biofilm formation have been scarcely investigated. The increasing prevalence of colibactin in E. coli and other Enterobacteriaceae and the recently described correlation with biofilm formation, makes colibactin a promising therapeutic target to prevent biofilm formation and its associated adverse effects.

Keywords: Escherichia coli, antimicrobial resistance, virulence, biofilm, colibactin

\section{INTRODUCTION}

Escherichia coli is a well-characterized bacterium which plays an essential role in the human microbiome. Nevertheless, some strains are responsible for intestinal and extraintestinal infections. Extraintestinal pathogenic E. coli (ExPEC) strains are commonly implicated in a variety of infectious diseases occurring in either the community or healthcare settings worldwide, resulting in high economic and social costs (Beloin et al., 2008; Blount, 2015; Manges et al., 2019).

Additionally, E. coli can form aggregates and attach to solid surfaces, forming complex structures called biofilms. Bacteria in biofilms secrete various components such as extracellular polymeric substances (EPS), which protect the bacterial community from host immunity and the effects of antibiotics, complicating the infection (Sharma et al., 2016).

In addition to the ability to form biofilms, the ExPEC group has many virulence factor genes (VFGs) encoding adhesins, toxins, siderophores, capsules, and invasins, which are often located into pathogenicity islands (PAIs), plasmids, and other mobile genetic elements (Sarowska et al., 2019). Some of these VFGs can promote biofilm formation. Among the well-characterized VFGs correlated with biofilm formation, type I fimbriae, curli fimbriae, and flagella are the most studied. The fimA gene encodes the major subunit of type I fimbriae, which are known to be involved in the first step of biofilm formation (Beloin et al., 2004). Curli fimbriae are encoded by curli-specific genes (csg) and are involved in adhesion to surfaces and invasion of eukaryotic host cells (Van Gerven et al., 2018). Flagella play an important role not only in cell motility but also in surface adhesion (Friedlander et al., 2015). Some studies suggest that deletion of some of these genes leads to a reduction in the ability to form biofilm (Guttenplan and Kearns, 2013; Smith et al., 2017).

One of the most recently studied VFGs is colibactin, a secondary metabolite encoded in the genomic island $p k s$, which interferes with the eukaryotic cell cycle and has been linked to colorectal cancer in humans (Dziubańska-Kusibab et al., 2020). Interestingly, this PAI is commonly observed among E. coli strains belonging to phylogroup B2, including ExPEC, and has been found in isolates from the intestinal microbiota, septicemia, neonatal meningitis, and urinary tract infections (UTIs) (Faïs et al., 2018; Dziubańska-Kusibab et al., 2020).

The aim of this study was to characterize 376 ExPEC strains in terms of antimicrobial resistance, biofilm formation, siderophore production, phylogroup classification, and presence of selected virulence and antimicrobial resistance genes. The association between these features and the ability to form biofilm was also analyzed. Understanding the VFGs that correlate with biofilm production is needed, as these could be considered targets for developing new antimicrobial therapies.

\section{MATERIALS AND METHODS}

\section{Bacterial Strains}

A total of 376 ExPEC strains were collected from four hospitals in Catalonia, Spain, between 2016 and 2017. Of these, 132 were isolated from blood, 60 from respiratory samples (13 sputum, 12 bronchoalveolar aspirates, 4 tracheal samples, 2 pleural fluid, and 29 non-classified respiratory samples) and 184 from urine (1 from a urinary catheter and 183 from midstream urine). Strains were identified by matrix-assisted laser desorption ionization-time-of-flight mass spectrometry (MALDI-TOF) (Bruker Daltonik GmbH, Bremen, Germany). The modified score values suggested by the manufacturer were used: a score $\geq 2.3$ meant species identification; a score between 2.0 and 2.299 meant genus identification and probable species identification; a score between 1.7 and 1.9 meant probable genus identification; and a score $<1.69$ meant non-reliable identification. Only strains with a score $\geq 2.3$ classified as $E$. coli were included in the study. After that, the strains were stored in Skim Milk (Becton Dickinson) at $-80^{\circ} \mathrm{C}$.

\section{Biofilm Formation and Quantification}

To determine biofilm formation, we performed a protocol previously developed by our group (Cepas et al., 2020). Briefly, strains were cultured in Luria Bertani (LB) agar (Miller's LB AGAR, Condalab) for $18-24 \mathrm{~h}$ at $37^{\circ} \mathrm{C}$. Then, the cell suspension was prepared in $10 \mathrm{~mL} \mathrm{LB}$ broth and incubated for $18-24 \mathrm{~h}$ at $37^{\circ} \mathrm{C}$ with shaking $(180 \mathrm{rpm})$. After incubation, each culture was diluted 1:100 in M63 medium [13.5 g/L $\mathrm{KH}_{2} \mathrm{PO}_{4}, 2 \mathrm{~g} / \mathrm{L}$ $\left.\left(\mathrm{NH}_{4}\right)_{2} \mathrm{SO}_{4}, 5.0 \times 10^{-4} \mathrm{~g} / \mathrm{L} \mathrm{FeSO}_{4}, 1 \mathrm{~mL} 1 \mathrm{M} \mathrm{MgSO}_{4} .7 \mathrm{H}_{2} \mathrm{O}\right]$, supplemented with $0.25 \%$ glucose and tested in 96-well flatbottomed non-treated polystyrene microtiter plates with lids (Nunc ${ }^{\circledR}$ Edge 2.0, VWR International, Barcelona, Spain) at $30^{\circ} \mathrm{C}$ for $48 \mathrm{~h}$ under static conditions.

The supernatant was then removed and the biofilms were washed once with $1 \mathrm{x}$ PBS and dried at $65^{\circ} \mathrm{C}$. The plates were stained with crystal violet $2 \%(\mathrm{CV})$ for $10 \mathrm{~min}$, washed with $1 \mathrm{x}$ PBS, and dried at $65^{\circ} \mathrm{C}$. The $\mathrm{CV}$ was resuspended with glacial acetic acid 33\%, and the biomass was quantified by measuring the optical density at $580 \mathrm{~nm}$ using a microplate reader (EPOCH 2 microplate reader; BioTek, VT). The experiment was performed in three technical and biological replicates, and the results were interpreted according to the criteria of 
Stepanović et al. (2007). Thus, the strains were classified as nonbiofilm formers (OD $\leq 0.150)$, weak biofilm formers $(\geq 0.151$ $\mathrm{OD} \leq 0.300)$, moderate biofilm formers $(\geq 0.301 \mathrm{OD} \leq 0.60)$, or strong biofilm formers ( $\mathrm{OD} \geq 0.601)$. Escherichia coli ATCC 25922 was used as positive control, and M63 broth without bacterial inoculum was used as negative control.

\section{Antimicrobial Susceptibility Testing}

Antimicrobial resistance profiling was performed using the most representative antimicrobial agents from the different antibiotic families, which are of great clinical and epidemiological relevance. Kirby-Bauer disk diffusion or broth microdilution methods (in the case of colistin) were done according to Clinical and Laboratory Standards Institute (CLSI) guidelines (CLSI, 2020). Escherichia coli ATCC 25922 was used as a control strain. The antimicrobials tested by disk diffusion were: amoxicillin/clavulanate $(20 / 10 \mu \mathrm{g})$, ampicillin $(10 \mu \mathrm{g})$, aztreonam $(30 \mu \mathrm{g})$, cefepime $(30 \mu \mathrm{g})$, cefotaxime $(30 \mu \mathrm{g})$,

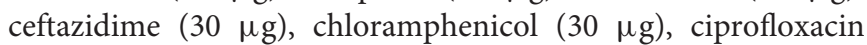
(5 $\mu \mathrm{g}$ ), fosfomycin (200 $\mu \mathrm{g} / 50 \mu \mathrm{g}$ of glucose-6-phosphate), gentamicin $(10 \mu \mathrm{g})$, imipenem $(10 \mu \mathrm{g})$, meropenem $(10 \mu \mathrm{g})$, and trimethoprim-sulfamethoxazole $(1.25 / 23.75 \mu \mathrm{g})$ (Becton Dickinson). Extended-spectrum beta-lactamases were screened by the ESBL test following the CLSI guidelines (CLSI, 2020). Isolates were classified as susceptible, resistant to 1 or 2 antimicrobial categories, multidrug-resistant (MDR) if resistant to at least one agent in $\geq 3$ antimicrobial categories; or extensively drug-resistant (XDR), if resistant to at least one agent in all but two or fewer antimicrobial categories (Magiorakos et al., 2012).

\section{Identification of Antimicrobial Resistance Genes}

Polymerase chain reaction (PCR) assays were performed using the supernatant of a boiled cell suspension of each isolate as DNA template. $\beta$-lactamase-encoding genes $b l a_{S H V-1}, b l a_{T E M-1}$ and the five major groups bla $a_{C T X-M:} b l a_{C T X-M-1}, b l a_{C T X-M-2}, b l a_{C T X-M-8}$, $b l a_{C T X-M-9}$, and $b l a_{C T X-M-25}$ were detected, as well as genes conferring resistance to sulfonamides (sul1 and sul2), quinolones [qnrB and $\left.a a c\left(6^{\prime}\right)-l b-c r\right]$ and colistin ( $m c r-1, m c r-2, m c r-3, m c r-4$ and $m c r-5)$. Previously characterized strains from our laboratory collection were used as positive controls of the different genes in the corresponding PCR experiments. Water was used as negative control. The PCR products from the strains were sequenced (Genewiz). The obtained sequences were compared with those of the corresponding genes available in the GenBank. Primer sequences (Condalab, Spain) used in the study of antimicrobial resistance genes are listed in Table $\mathbf{1 .}$

\section{Virulence Determinants Detection}

Virulence factor genes encoding for adhesins (fimH-1, sfa, papA, pgaA), siderophores (iroN, iutA, irp-1, iucA) and toxins (hlyA, $c n f-1, c l b A c l b B, c l b N$ and $c l b Q)$ were detected by PCR. To determine the presence of the complete $p k s$ genomic island, primers for the four most representative genes were used: $c l b A$ and $c l b Q$ as flanking primers, and $c l b B$ and $c l b N$ as internal primers (Johnson et al., 2008; Dubois et al., 2010;
Suresh et al., 2018). The primer sequences (Condalab, Spain) used for the detection of the different VFGs are listed in Table 2. Previously characterized strains carrying the different VFGs were used as positive controls. Water was used as negative control.

\section{Siderophore Assay}

Siderophores production was determined according to the protocol described by Schwyn and Neiland (Schwyn and Neilands, 1987). Briefly, bacterial strains were cultured on chrome azurol S (CAS) (VWR) and hexadecyltrimethylammonium bromide (HDTMA) plates (Fisher Scientific). If a bacterium excretes a siderophore that removes iron from the dye complex, the color of the agar changes from blue to orange. Acinetobacter baumannii ATCC19606 was used as positive control.

\section{Phylogroup Assignment Method}

Escherichia coli strains were classified into seven phylogroups (A, B1, B2, C, D, E, and F) according to the PCR method designed by Clermont et al. (2013). Strains belonging to our group and whose phylogroup was previously identified were used as controls.

\section{Typing of Colibactin-Positive Strains by Pulsed-Field Gel Electrophoresis}

Due to the high prevalence of colibactin among the studied strains, we decided to analyze their clonal relationship by pulsed-field gel electrophoresis (PFGE) of XbaI-digested DNA, following the protocol described by Durmaz et al. (2009). The profiles obtained were compared using the InfoQuestTM FPv.5.4 software (Bio-Rad Laboratories) and the unweighted pair group method with arithmetic mean to create dendrograms based on Dice's similarity coefficient. Isolates were clustered together if their similarity index was $\geq 85 \%$.

\section{Statistical Analysis}

Statistical analyses were performed using IBM SPSS Statistics for Windows software, version 21.0. The Chi-square test was used to evaluate correlations among variables. p-values $<0.05$ were considered statistically significant.

\section{RESULTS}

\section{Biofilm Formation and Quantification}

Escherichia coli strains were analyzed for biofilm formation using M63 broth. Fifty-nine strains (15.7\%) were classified as nonbiofilm-forming isolates, $87(23.1 \%)$ were classified as weakly biofilm-forming, 134 (35.6\%) as moderately biofilm-forming, and $96(25.6 \%)$ as strongly biofilm-forming strains.

Furthermore, the ability to form biofilm was investigated according to the origin of the isolates (urine, blood or respiratory tract) as shown in Figure 1; however, no correlation between strain source and biofilm formation ability was found $(p>0.05)$.

\section{Antimicrobial Susceptibility Testing}

The percentages of antimicrobial resistance are shown in Figure 2. Overall, the highest percentages of antibiotic resistance 
TABLE 1 | Primers to detect antimicrobial resistance genes.

\begin{tabular}{|c|c|c|c|c|}
\hline Target gene & Primer sequence $\left(5^{\prime} \rightarrow 3^{\prime}\right)$ & Melting Temperature $\left(\mathrm{Tm}^{\circ} \mathrm{C}\right)$ & Product size (bp) & References \\
\hline blatEM-1 - F & TCGCCGCATACACTATTCTCAGAATGA & 53 & 445 & Monstein et al., 2007 \\
\hline blatEM-1 - R & ACGCTCACCGGCTCCAGATTTAT & & & \\
\hline$b a_{S H V-1}-F$ & ATGCGTTATATTCGCCTGTG & 49 & 747 & Wiegand et al., 2007 \\
\hline blasHV-1 - R & TGCTITGTTATTCGGGCCAA & & & \\
\hline blactX-M-1 - F & AAAAATCACTGCGCCAGTTC & 52 & 415 & Woodford et al., 2006 \\
\hline bla $_{C T X-M-1}-\mathrm{R}$ & AGCTTATTCATCGCCACGTT & & & \\
\hline bla $_{C T X-M-2}-F$ & CGACGCTACCCCTGCTATT & 52 & 552 & Woodford et al., 2006 \\
\hline bla $C T X-M-2-R$ & CCAGCGTCAGATIITCAGG & & & \\
\hline blactX-M-9 - F & CAAAGAGAGTGCAACGGATG & 52 & 205 & Woodford et al., 2006 \\
\hline bla ${ }_{C T X-M-9}-\mathrm{R}$ & ATTGGAAAGCGTTCATCACC & & & \\
\hline bla $_{C T X-M-8}-\mathrm{F}$ & TCGCGTTAAGCGGATGATGC & 52 & 666 & Woodford et al., 2006 \\
\hline bla & AACCCACGATGTGGGTAG & & & \\
\hline bla $C T X-M-25-F$ & GCACGATGACATTCGGG & 52 & 327 & Woodford et al., 2006 \\
\hline bla $C T X-M-25-R$ & AACCCACGATGTGGGTAG & & & \\
\hline bla $_{C T X-M-15 / 28}-\mathrm{F}$ & ATAAAACCGGCAGCGGTG & 55 & 483 & Leflon-Guibout et al., 2004 \\
\hline blactX-M-15/28- R & GAATITGACGATCGGGG & & & \\
\hline bla & CGCTIATGCGCAGACGA & 57 & 785 & Pai et al., 2001 \\
\hline bla $_{C T X-M-14 / 27^{-}} \mathrm{R}$ & GATTCTCGCCGCTGAAGC & & & \\
\hline sul1 - F & CTTCGATGAGAGCCGGCGGC & 63 & 436 & Guerra et al., 2004 \\
\hline sul1 - R & GCAAGGCGGAAACCCGCGCC & & & \\
\hline sul2 - F & TCAACATAACCTCGGACAGT & 55 & 707 & Guerra et al., 2004 \\
\hline sul2 - R & GATGAAGTCAGCTCCACCT & & & \\
\hline$a a c\left(6^{\prime}\right)-1 b-c r-F$ & TTGCGATGCTCTATGAGTGGCTA & 60 & 482 & Park et al., 2006 \\
\hline$a a c\left(6^{\prime}\right)-I b-c r-R$ & CTCGAATGCCTGGCGTGTाT & & & \\
\hline$q n r B-F$ & GATCGTGAAAGCCAGAAAGG & 52 & 469 & Robicsek et al., 2006 \\
\hline$q n r B-\mathrm{R}$ & ACGATGCCTGGTAGTTGTCC & & & \\
\hline$m c r-1-F$ & ATGCCAGTTCTITCGCGTG & 59 & 502 & Lescat et al., 2018 \\
\hline$m c r-1-\mathrm{R}$ & TCGGCAAATTGCGCTITGGC & & & \\
\hline$m c r-2-F$ & GATGGCGGTCTATCCTGTAT & 59 & 379 & Lescat et al., 2018 \\
\hline$m c r-2-\mathrm{R}$ & AAGGCTGACACCCCATGTCAT & & & \\
\hline$m c r-3-F$ & ACCAGTAAATCTGGTGGCGT & 59 & 296 & Lescat et al., 2018 \\
\hline$m c r-3-\mathrm{R}$ & AGGACAACCTCGTCATAGCA & & & \\
\hline$m c r-4-F$ & TTGCAGACGCCCATGGAATA & 59 & 207 & Lescat et al., 2018 \\
\hline$m c r-4-\mathrm{R}$ & GCCGCATGAGCTAGTATCGT & & & \\
\hline$m c r-5-F$ & GGACGCGACTCCCTAACTTC & 59 & 608 & Lescat et al., 2018 \\
\hline$m c r-5-\mathrm{R}$ & ACAACCAGTACGAGAGCACG & & & \\
\hline
\end{tabular}

were observed with ciprofloxacin (48.7\%), trimethoprimsulfamethoxazole (47.9\%), and ampicillin (38\%). Only two strains were resistant to colistin $(0.5 \%)$, and one to fosfomycin $(0.3 \%)$. None was resistant to carbapenems (imipenem or meropenem). To determine whether biofilm formation correlates with antimicrobial resistance, the different categories of biofilm formation were compared with resistance profiles as shown in Figure 3. Non-biofilm-forming strains showed higher percentages of resistance to ciprofloxacin (74.6\%) compared to biofilm-forming strains (Figure $3 \mathbf{H}$ ). Thus, the higher the resistance to ciprofloxacin, the lower the biofilm production ability $(p<0.0001)$.

Regarding the antimicrobial resistance classification, 91 strains $(24.2 \%)$ were susceptible to all the antimicrobial categories tested, $142(37.8 \%)$ were resistant to one or two antimicrobial categories, 143 (38\%) isolates were MDR, and none was XDR. The percentages for biofilm formation by antimicrobial resistance classification are shown in Figure 4. A direct relationship between antimicrobial susceptibility and ability to form biofilm was observed. However, no statistical relationship was found between biofilm formation ability and the antimicrobial resistance classification $(p=0.053)$.

\section{Identification of Antimicrobial Resistance Genes}

In total, 73 (19.4\%) isolates were found to be ESBL-producing strains. The most common $\beta$-lactamase-encoding gene was bla $a_{C T X-M-15}(n=43,58.9 \%)$, followed by bla $n$ TEM-1 $(n=33$, $45.2 \%), b_{C T X-M-14}(n=8,12.3 \%), b_{\text {bHV-1 }}(n=7,9.6 \%)$, bla $a_{C T X-M-27}(n=5,6.8 \%)$ and bla $(n T X-M-28(n=3,4.1 \%)$. None carried the $b l a_{C T X-M-2}, b l a_{C T X-M-8}$ or bla $a_{C T X-M-25}$ genes, but 27 strains (37\%) harbored more than one $\beta$-lactamaseencoding gene. 
TABLE 2 | Primers to detect virulence factor genes.

\begin{tabular}{|c|c|c|c|c|c|}
\hline Target gene & Primer sequence $\left(5^{\prime} \rightarrow 3^{\prime}\right)$ & $\begin{array}{l}\text { Melting temperature } \\
\qquad\left(\operatorname{Tm}^{\circ} \mathrm{C}\right)\end{array}$ & $\begin{array}{l}\text { Product size } \\
\text { (bp) }\end{array}$ & Function & References \\
\hline $\operatorname{iroN}-\mathrm{F}$ & AAGTCAAAGCAGGGGTTGCCCG & 56 & 827 & $\begin{array}{l}\text { Siderophore uptake } \\
\text { transmembrane transporter } \\
\text { activity }\end{array}$ & Johnson et al., 2000 \\
\hline $\operatorname{iroN}-\mathrm{R}$ & GACGCCGACATTAAGACGCAG & & & & \\
\hline $\operatorname{irp1}-\mathrm{F}$ & GGCGTCTCCTCCTITGGTATT & 60 & 1729 & $\begin{array}{l}\text { Gene encoding for an iron } \\
\text { regulatory protein }\end{array}$ & Xu et al., 2000 \\
\hline irp1-R & GTGATTCCCGCTGTTGATGTT & & & & \\
\hline$i u c A-F$ & AGTCTGCATCTTAACCTTCA & 56 & 1100 & Gene encoding for an aerobactin & Guerrieri et al., 2019 \\
\hline $\operatorname{iuc} A-\mathrm{R}$ & CTCGTTATGATCGTTCAGAT & & & & \\
\hline papA - F & ATGGCAGTGGTGTCTITGGTG & 62 & 717 & $\begin{array}{l}\text { Fimbrial major pilin protein } \\
\text { precursor }\end{array}$ & $\begin{array}{l}\text { Johnson and Stell, } \\
2000\end{array}$ \\
\hline papA - R & CGTCCCACCATACGTGCTCTTC & & & & \\
\hline$f i m H-F$ & CAGCGATGATITCCAGTITGTGTG & 59 & 461 & $\begin{array}{l}\text { Type } 1 \text { fimbrin D-mannose } \\
\text { specific adhesin precursor }\end{array}$ & $\begin{array}{l}\text { Sáez-López et al., } \\
2017\end{array}$ \\
\hline$f i m H-R$ & TGCGTACCAGCATTAGCAATGTCC & & & & \\
\hline$s f a-F$ & CTCCGGAGAACTGGGTGCATCTTAC & 65 & 410 & S fimbriae & Houdouin et al., 2006 \\
\hline$s f a-R$ & CGGAGGAGTAATTACAAACCTGGCA & & & & \\
\hline$c n f-1-F$ & AAGATGGAGTICCTATGCAGGAG & 56 & 498 & Cytotoxic necrotizing factor & Takahashi et al., 2006 \\
\hline$c n f-1-\mathrm{R}$ & САTTCAGAGTCCTGCССTCATTATT & & & & \\
\hline hlyA - F & AACAAGGATAAGCACTGTTCTGGC & 59 & 1177 & Hemolysin & $\begin{array}{l}\text { Johnson and Stell, } \\
2000\end{array}$ \\
\hline hlyA - R & ACCATATAAGCGGTCATTCCCGTCA & & & & \\
\hline iutA - F & GGCTGGACATCATGGGAACTGG & 60 & 300 & $\begin{array}{l}\text { Ferric aerobactin receptor } \\
\text { precursor }\end{array}$ & $\begin{array}{l}\text { Johnson and Stell, } \\
2000\end{array}$ \\
\hline $\operatorname{iut} A-\mathrm{R}$ & CGTCGGGAACGGGTAGAATCG & & & & \\
\hline$p g a A-F$ & GGCTTGAAACTTCTTACTGC & 60 & 209 & $\begin{array}{l}\text { Poly-beta-1,6-N-acetyl-D- } \\
\text { glucosamine export } \\
\text { protein }\end{array}$ & Shrestha et al., 2019 \\
\hline$p g a A-R$ & CCTGTITATCTTGCCCGGCC & & & & \\
\hline$c / b Q-F$ & CTTGTATAGTTACACAACTATITC & 54 & 821 & $\begin{array}{l}\text { Colibactin biosynthesis } \\
\text { thioesterase } \mathrm{ClbQ}\end{array}$ & Morgan et al., 2019 \\
\hline$c / b Q-R$ & TTATCCTGTTAGCTITCGTTC & & & & \\
\hline$c / b A-F$ & CTAGATTATCCGTGGCGATTC & 54 & 1002 & $\begin{array}{l}\text { Colibactin biosynthesis } \\
\text { phosphopantetheinyl transferase } \\
\text { ClbA }\end{array}$ & Morgan et al., 2019 \\
\hline$c / b A-R$ & CAGATACACAGATACCATTCA & & & & \\
\hline$c / b B-F$ & GATTTGGATACTGGCGATAACCG & 54 & 579 & $\begin{array}{l}\text { Colibactin hybrid non-ribosomal } \\
\text { peptide synthetase/type I } \\
\text { polyketide synthase ClbB }\end{array}$ & Johnson et al., 2008 \\
\hline$c / b B-R$ & CCATITCCCGTITGAGCACAC & & & & \\
\hline$c / b N-F$ & GIITGCTCGCCAGATAGTCATTC & 54 & 733 & $\begin{array}{l}\text { Colibactin non-ribosomal peptide } \\
\text { synthetase ClbN }\end{array}$ & Johnson et al., 2008 \\
\hline$c / b N-R$ & CAGTTCGGGTATGTGTGGAAGG & & & & \\
\hline
\end{tabular}

Regarding biofilm formation, 17 of the ESBLs-producing strains $(23.3 \%)$ were non-biofilm-formers, 15 (20.5\%) were weak biofilm-formers, 25 (34.2\%) were moderate biofilmformers, and 16 (21.9\%) were strong biofilm-formers. However, no relationship was found between ESBL production and biofilm formation.

Of the 190 strains resistant to trimethoprimsulfamethoxazole, 78 (41.1\%), 131 (68.9\%), and 47 strains (24.7\%) harbored sul1, sul2, or both genes, respectively.

Among the 188 quinolone-resistant strains, 6 (3.2\%) qnrB and $40(21.3 \%) a a c\left(6^{\prime}\right)-I b-c r$ genes were detected. We observed a higher prevalence of the aac (6')-Ib-cr gene among the non-biofilm-forming strains, being the correlation statistically significant $(p=0.008)$. We detected two colistin-resistant strains, one of which carried the $m c r-1$ gene.

\section{Virulence Determinants Detection}

The results about the prevalence of the different VFGs tested are shown in Figure 5. It was observed that the prevalence of siderophore-related genes was variable: $\operatorname{irp1}(77.1 \%)$, iutA (66.8\%), iucA (52.7\%), and iroN (45.5\%). A significant correlation was found between biofilm formation ability and the presence of 


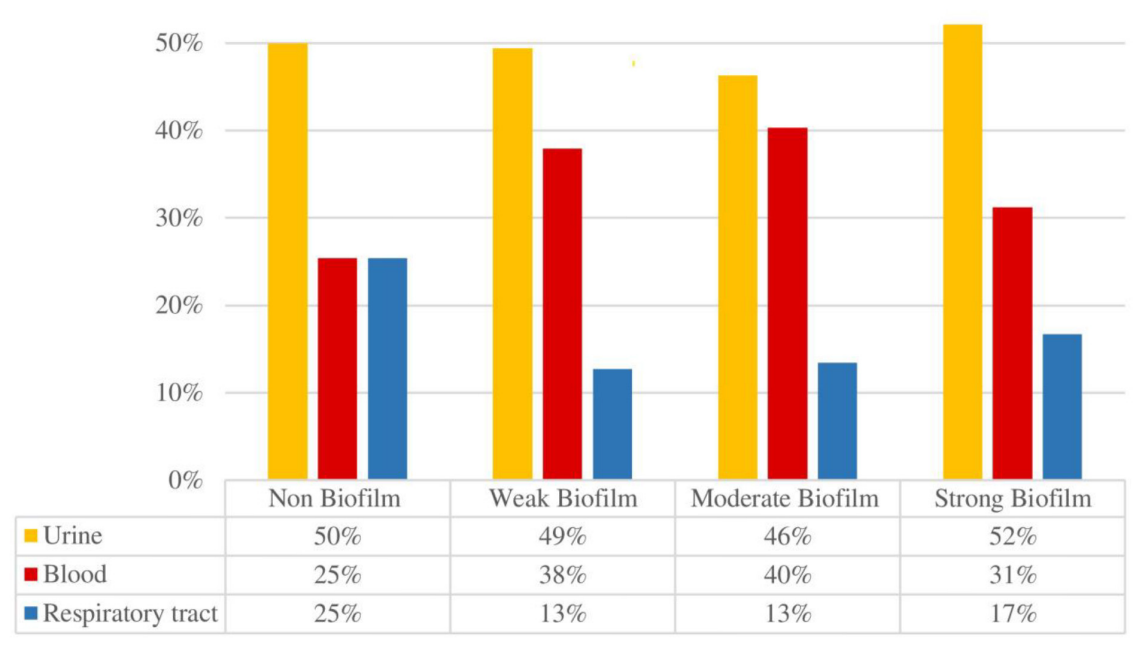

FIGURE 1 | Biofilm formation according to the origin of the isolates.

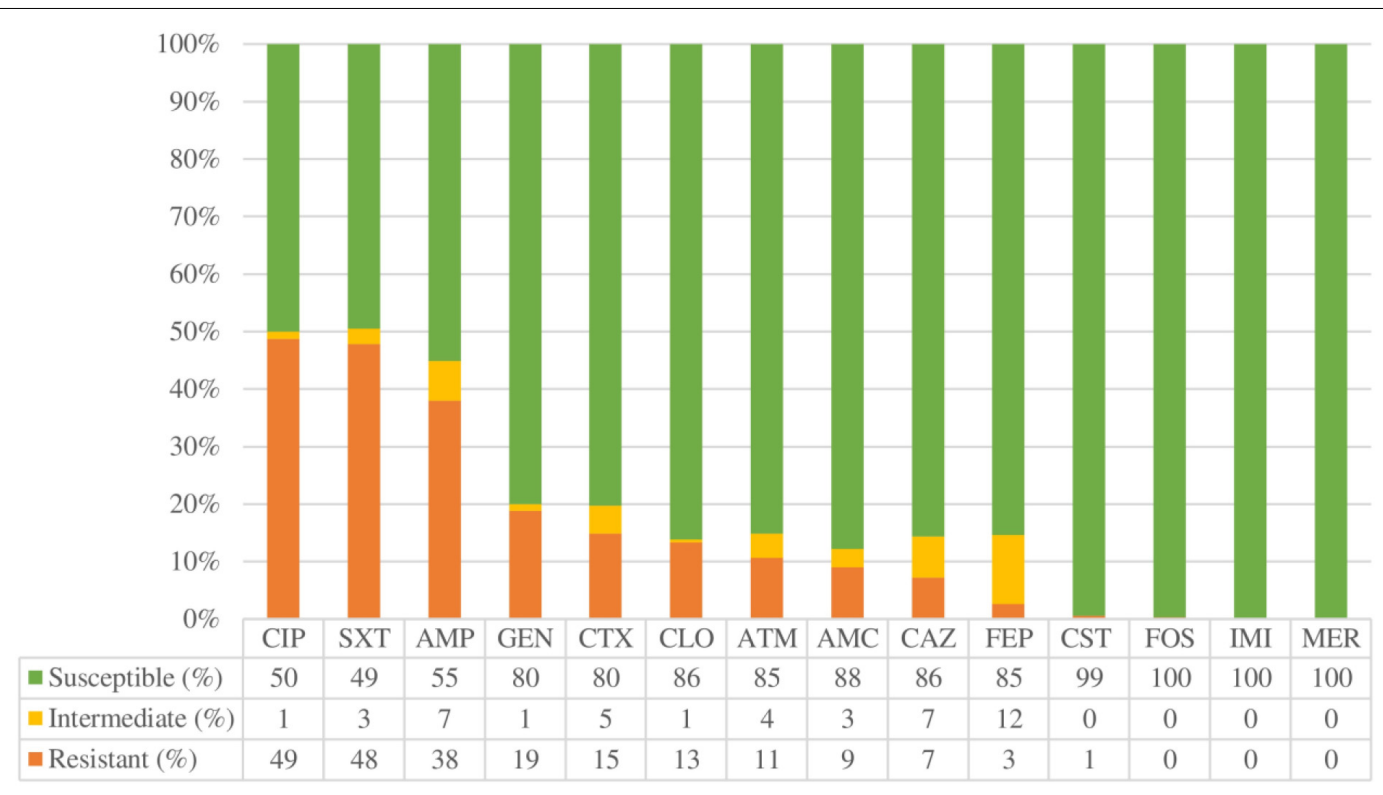

FIGURE 2 | Overall antimicrobial resistance rates expressed in percentage (\%). AMC: Amoxicillin/clavulanic acid, AMP: Ampicillin, ATM: Aztreonam, CLO: Chloramphenicol, CAZ: Ceftazidime, CIP: Ciprofloxacin, CST: Colistin, CTX: Cefotaxime, FEP: Cefepime, FOS: Fosfomycin, GEN: Gentamicin, IMI: Imipenem, MER: Meropenem, SXT: Trimethoprim-sulfamethoxazole.

$\operatorname{iroN}(p<0.001)$ or iutA $(p=0.010)$ genes. However, iutA gene was more prevalent among non-biofilm-forming strains.

The adhesin-encoding genes fim $H$ and $p g a A$ were the most frequent genes among the strains, with a prevalence of $92 \%$ and $84.6 \%$, respectively. The prevalence of the other adhesinencoding genes, such as papA and $s f a$, was $43.1 \%$ and $21.8 \%$, respectively. A statistically significant correlation was found between biofilm formation and the presence of the $p a p A, f i m H$, and $s f a$ genes $(p<0.001)$.

Among the genes encoding toxins, hlyA and $c n f-1$ showed a prevalence of $25 \%$ and $24.7 \%$, respectively. The $c l b A, c l b B$, and $c l b N$ genes were present in $19.9 \%$ of the strains. $c l b Q$ gene was observed in $20.5 \%$ of the isolates. It is of note that a statistically significant correlation was confirmed between the presence of toxin-encoding genes and the ability to form biofilm: $h l y A(p=0.0002), c n f(p<0.001)$, and colibactin-encoding genes $(c l b A, c l b B, c l b N$ and $c l b Q)(p<0.001)$.

\section{Siderophore Assay (Chrome Azurol S Test)}

The 376 isolates were screened on CAS agar plates, a useful method for identifying siderophores in E. coli isolates and other Gram-negative bacteria. 199 (52.9\%) siderophore-producing 

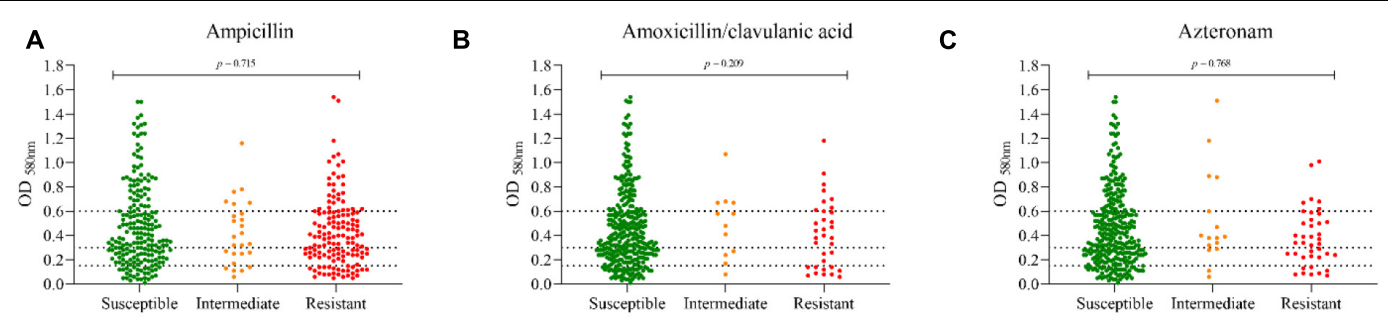

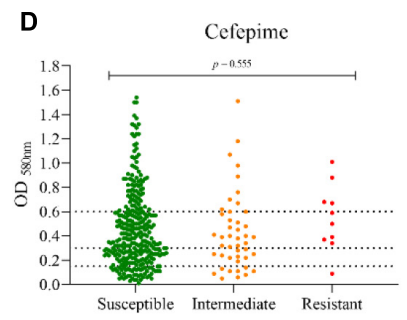

E

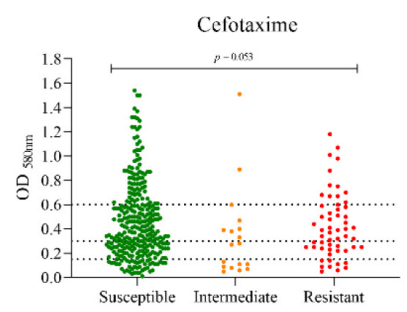

H
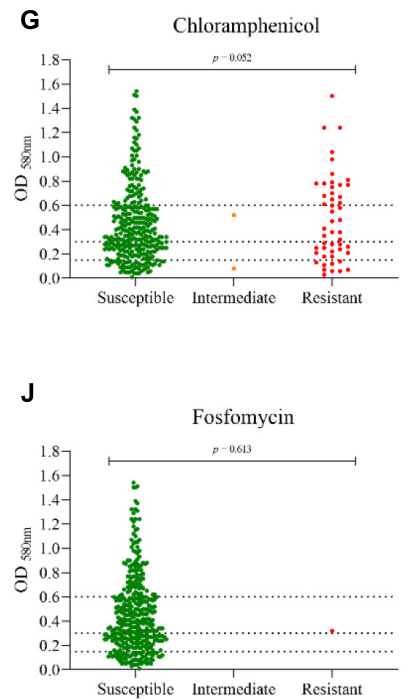

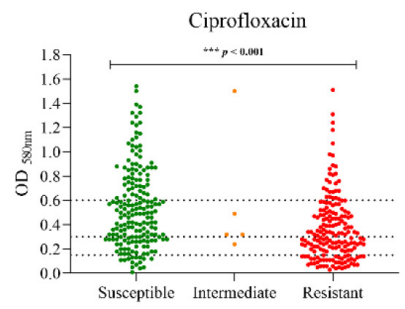

$\mathbf{K}$

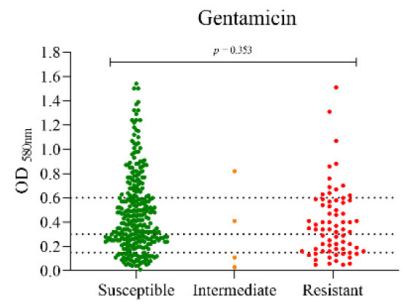

$\mathbf{F}$

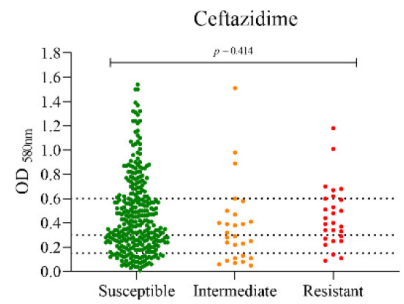

I

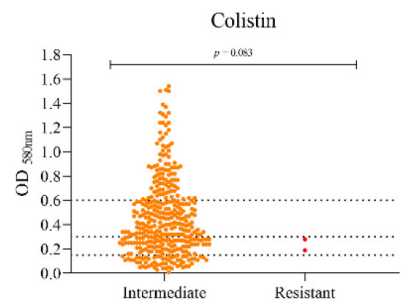

$\mathbf{L}$

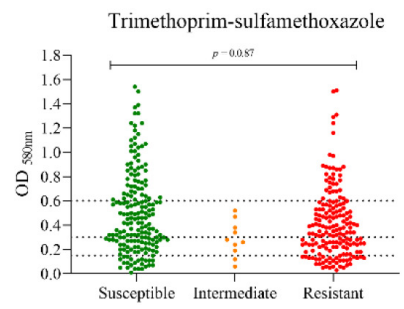

FIGURE 3 | Distribution of biofilm formation among the different antibiotic resistance profiles. (A) Ampicillin; (B) Amoxicillin/Clavulanic acid; (C) Aztreonam; (D) Cefepime; (E) Cefotaxime; (F) Ceftazidime; (G) Chloramphenicol; (H) Ciprofloxacin; (I) Colistin; (J) Fosfomycin; (K) Gentamicin;

(L) Trimethoprim-sulfamethoxazole. The dotted lines indicate the cut-off points for each biofilm category [non-biofilm formers (OD $\leq 0.150)$, weak biofilm formers $(\geq 0.151 \mathrm{OD} \leq 0.300)$, moderate biofilm formers $(\geq 0.301 \mathrm{OD} \leq 0.60)$, or strong biofilm formers $(\mathrm{OD} \geq 0.601)]$.

strains were found, as shown in Figure 5, but statistical analysis showed no relationship between CAS test positivity and biofilm formation $(p=0.132)$.

On the other hand, a statistically significant association between the positive CAS method and the presence of different siderophore-encoding genes irp1, iucA, iutA $(p<0.001)$ was found. The presence of the fimbriae $\mathrm{H}$ coding gene $(\mathrm{fimH})$ was also correlated with the CAS test $(p=0.025)$. Contrarily, an association between the CAS test and the absence of the sfa gene ( $p=0.024)$ was observed.

It is to note that strains resistant to antibiotics such as gentamicin $(p=0.032)$, ampicillin $(p=0.001)$, cefotaxime $(p=0.001)$, ceftazidime $(p=0.002)$, cefepime $(p=0.001)$ or aztreonam $(p<0.001)$ showed high siderophore production (positive CAS test). Likewise, ESBL-producing strains were statistically associated with a positive CAS test $(p=0.001)$. Finally, strains belonged to phylogroup B2 produced more siderophores than strains belonging to the other phylogroups $(p<0.001)$.

\section{Phylogroup Assignment Method}

In our study, the phylogenetic groups considered more virulent B2 and D, accounted for $72.9 \%$ of the $E$. coli isolates [B2: $n=235$ (62.5\%); D: $n=39(10.4 \%)]$. The less virulent groups were found in varying percentages [A: $n=18(4.8 \%) ; \mathrm{B} 1: n=31(8.2 \%)$; 


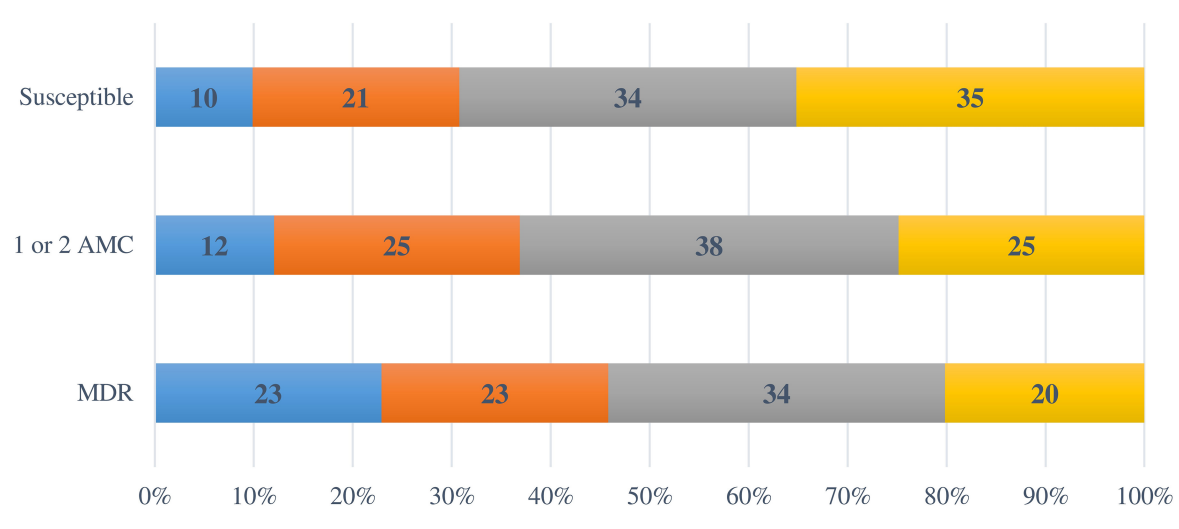

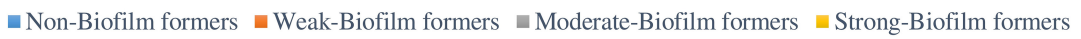

FIGURE 4 | Biofilm formation according to the antimicrobial resistance classification. AMC: Antimicrobial categories; MDR: Multidrug-resistant.

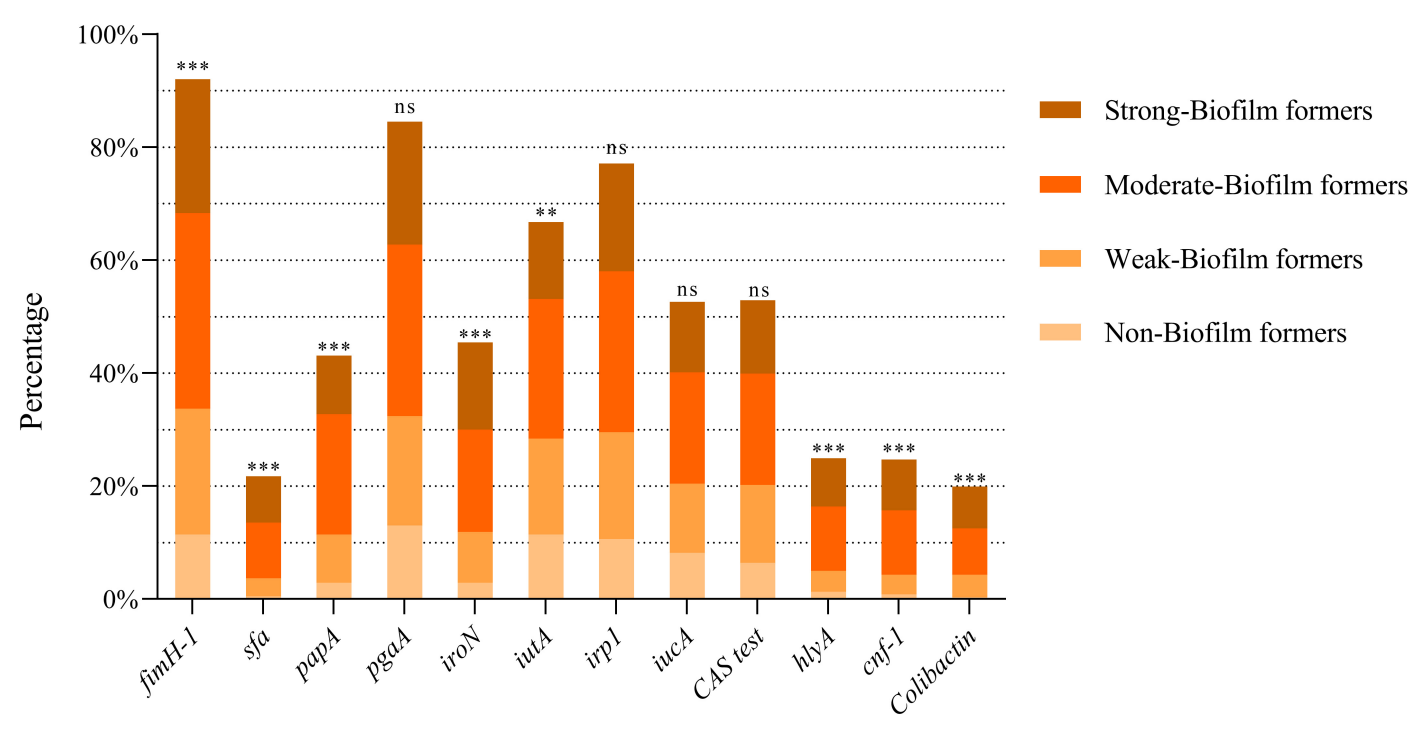

Virulence determinants

FIGURE 5 | Prevalence of the different VFGs tested according to the biofilm formation ability. Each bar shows the percentage of positivity of each gene within the total strains studied. Within each bar, the percentage according to the ability to form biofilms is shown. ${ }^{* * *} p<0.001$; ${ }^{* *} p=0.01$; ns: not significant ( $p>0.05$ ).

C: $n=18(4.8 \%) ; \mathrm{E}: n=4$ (1.1\%); F: $n=26$ (6.9\%); unknown: $n=5(1.3 \%)]$.

According to biofilm classification, a great variety of phylogroups was observed in the non-biofilm-forming strains group. In contrast, a direct relationship between the ability to form biofilm and phylogroup B2 was observed, being this relationship statistically significant $(p<0.001)$ (Figure 6).

\section{Characterization of Colibactin-Encoding Escherichia coli Strains}

The presence of $c l b A, c l b B, c l b N$, and $c l b Q$ genes confirmed the full presence of the $p k s$-island in 75 strains. Among these, 74 presented the ability to form biofilm. We compared whether the presence of colibactin-encoding genes was related to biofilm formation ability and we found a statistically significant relationship between these two variables $(p<0.001)$.

As shown in Table 3, colibactin-producing strains showed a high prevalence of most of the VFGs tested (iroN, irp1, $p a p A$, fim $H, c n f, h l y A, p g a A$, and $s f a)(p<0.05)$, but had a low prevalence of the iucA and iutA genes. The relationship between susceptibility to most of the antimicrobials tested (amoxicillin/clavulanic acid, ampicillin, aztreonam, cefepime, cefotaxime, ceftazidime, chloramphenicol, ciprofloxacin, gentamicin, and trimethoprim-sulfamethoxazole) and the presence of colibactin genes was statistically significant $(p<0.05)$. Only two of the colibactin-encoding strains were ESBL-producers, showing an inverse correlation between colibactin genes and ESBL production $(p<0.001)$. Most colibactin-positive strains were isolated from urine $(n=45$; 
A

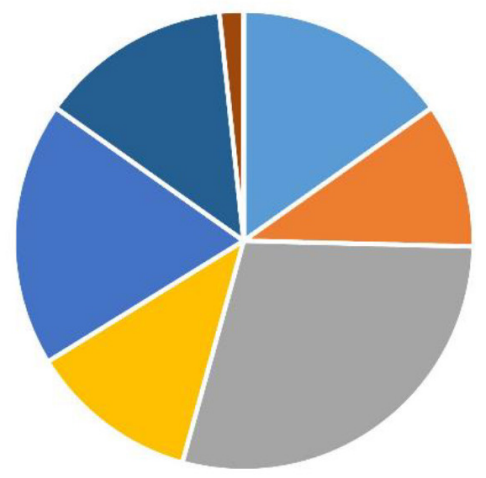

- A

- B1

" $\mathrm{B} 2$

$=\mathrm{C}$

- $\mathrm{D}$

- E

- $\mathrm{F} \quad 13.5 \%$

- UNK $1.7 \%$
$15.2 \%$

$10.2 \%$

$28.9 \%$

$11.9 \%$

$18.6 \%$

$0 \%$

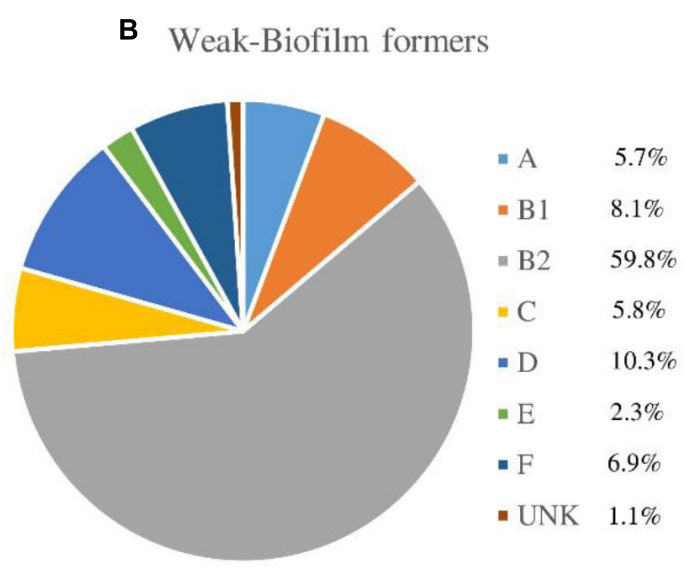

D Strong-Biofilm formers

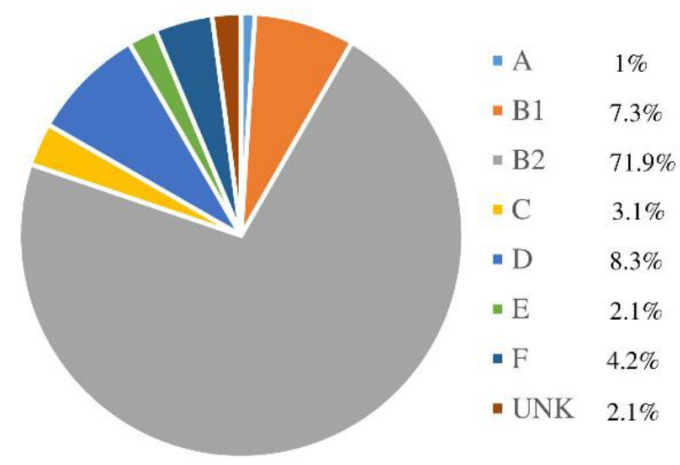

FIGURE 6 | Phylogroup assignment according to the biofilm formation. UNK: Unknown. (A) Non-Biofilm former strains. (B) Weak-Biofilm former strains. (C) Moderate-Biofilm former strains. (D) Strong-Biofilm former strains.

$60 \%)$, followed by strains from blood $(n=22 ; 29.3 \%)$, and the respiratory tract $(n=8 ; 10.7 \%)$, but no correlation was found between the strain source and the presence of colibactin-encoding genes.

The majority of the colibactin-positive strains belonged to phylogroup B2, and the analysis of the clonal relatedness by PFGE of the colibactin-positive E . coli strains showed 48 different clusters with a Dice similarity index $\geq 85 \%$. This indicates that the E. coli isolates harboring the colibactin toxin exhibit a high clonal diversity (Figure 7).

\section{DISCUSSION}

Extraintestinal pathogenic E. coli strains are a group of bacteria that can cause urinary tract, bloodstream and other non-intestinal infections, both in healthcare settings and in the community (Manges et al., 2019). Several studies have investigated the association between antimicrobial resistance and/or the presence of some VFGs and the ability to form biofilms (May and Okabe, 2011; Friedlander et al., 2015; Cepas et al., 2019). However, the virulence genes described in recent years need to be studied in more detail, as they may be related to biofilm formation. In this study, we characterized 376 strains to investigate the possible relationship between antimicrobial resistance and/or the presence of selected virulence determinants and the ability to form biofilms. Our results showed that almost all the isolates studied (84.3\%) were able to form biofilms, and this high rate might be related to some of the genes and features observed among the strains studied.

In terms of antimicrobial resistance, we found high rates of resistance to ciprofloxacin (48.7\%), trimethoprimsulfamethoxazole (47.9\%), and ampicillin (38\%), and fully susceptible strains to carbapenems (imipenem and meropenem). Comparing our results with the SMART study (Cantón et al., 2021), which investigated Gram-negative bacilli isolated from intra-abdominal, urinary, bloodstream and lower respiratory tract infection from 2016 to 2018 in 11 participating Spanish Hospitals, we found similar resistance rates for cephalosporines, carbapenems and colistin but their antimicrobial resistance rates to ciprofloxacin were lower $(32.3 \%)$. Besides, they found a lower rate of ESBL-producing strains (8.6\%). According to the data from the 2017 European Antimicrobial Resistance Surveillance Network report (European Centre for Disease Prevention and Control [ECDC], 2017), which is based on antimicrobial resistance data from invasive isolates, we 
TABLE 3 | Characterization of colibactin-encoding Escherichia coli strains.

\begin{tabular}{|c|c|c|c|c|c|c|c|c|c|c|c|c|c|c|c|c|c|c|c|c|}
\hline \multirow[b]{2}{*}{ 苛 } & \multirow[b]{2}{*}{ 荡 } & \multirow{2}{*}{$\begin{array}{l}\text { 을 } \\
\frac{0}{2} \\
\frac{0}{2} \\
\frac{0}{2}\end{array}$} & \multirow[b]{2}{*}{ 晋 } & \multicolumn{4}{|c|}{ Adhesines } & \multicolumn{5}{|c|}{ Siderophores } & \multicolumn{4}{|c|}{ Toxins } & \multicolumn{4}{|c|}{ ARGs } \\
\hline & & & & $\underset{\Xi}{\mathbb{\Xi}}$ & $\grave{n}$ & $\underset{\Omega}{\mathbb{Z}}$ & $\begin{array}{l}\mathbb{S} \\
8 \\
8 \\
2\end{array}$ & $\sum_{:}$ & $\underset{\Xi}{\mathbb{Z}}$ & $\widehat{\widehat{\Omega}}$ & $\underset{S}{J}$ & $\underset{\tilde{U}}{\stackrel{\tilde{z}}{E}}$ & $\underset{\Sigma}{\Xi}$ & 5 & $\underset{\Xi}{\mathbb{S}}$ & 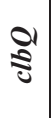 & 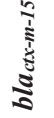 & 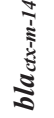 & $\underset{\Xi}{\Xi}$ & $\underset{5}{\mathbb{N}}$ \\
\hline HUB561 & Urine & B2 & Moderate & & & & & & & & & & & & & & & & & \\
\hline HUB562 & Urine & B2 & Moderate & & & & & & & & & & & & & & & & & \\
\hline HUB564 & Urine & B2 & Weak & & & & & & & & & & & & & & & & & \\
\hline HUB569 & Urine & B2 & Strong & & & & & & & & & & & & & & & & & \\
\hline HCB0012 & Blood & B2 & Moderate & & & & & & & & & & & & & & & & & \\
\hline HMT142 & Blood & B2 & Strong & & & & & & & & & & & & & & & & & \\
\hline HCB0015 & Blood & B2 & Strong & & & & & & & & & & & & & & & & & \\
\hline НMT0019 & Urine & B2 & Moderate & & & & & & & & & & & & & & & & & \\
\hline HCB0029 & Blood & B2 & Moderate & & & & & & & & & & & & & & & & & \\
\hline HCB0031 & Blood & B2 & Moderate & & & & & & & & & & & & & & & & & \\
\hline HCB0035 & Blood & B2 & Strong & & & & & & & & & & & & & & & & & \\
\hline HCB881 & Blood & B2 & Strong & & & & & & & & & & & & & & & & & \\
\hline HCB0038 & Blood & B2 & Weak & & & & & & & & & & & & & & & & & \\
\hline НCB0039 & Blood & B2 & Moderate & & & & & & & & & & & & & & & & & \\
\hline HCB0042 & Urine & B2 & Strong & & & & & & & & & & & & & & & & & \\
\hline НCB0044 & Urine & B2 & Moderate & & & & & & & & & & & & & & & & & \\
\hline HCB0045 & Urine & B2 & Moderate & & & & & & & & & & & & & & & & & \\
\hline HCB0047 & Urine & $\mathrm{B} 2$ & Strong & & & & & & & & & & & & & & & & & \\
\hline HCB883 & Urine & B2 & Strong & & & & & & & & & & & & & & & & & \\
\hline HCB196 & Blood & B2 & Weak & & & & & & & & & & & & & & & & & \\
\hline HCB0113 & Respiratory & $\mathrm{B} 2$ & Moderate & & & & & & & & & & & & & & & & & \\
\hline HCB197 & Respiratory & $\mathrm{B} 2$ & Strong & & & & & & & & & & & & & & & & & \\
\hline НCB198 & Respiratory & B2 & Strong & & & & & & & & & & & & & & & & & \\
\hline НCB889 & Urine & $\mathrm{B} 2$ & Moderate & & & & & & & & & & & & & & & & & \\
\hline HCB143 & Urine & B2 & Strong & & & & & & & & & & & & & & & & & \\
\hline HCB150 & Urine & B2 & Strong & & & & & & & & & & & & & & & & & \\
\hline HCB154 & Urine & B2 & Weak & & & & & & & & & & & & & & & & & \\
\hline HUB576 & Urine & $\mathrm{B} 2$ & Strong & & & & & & & & & & & & & & & & & \\
\hline HUB582 & Blood & B2 & Moderate & & & & & & & & & & & & & & & & & \\
\hline HMT372 & Urine & B2 & Moderate & & & & & & & & & & & & & & & & & \\
\hline HMT378 & Urine & $\mathrm{B} 2$ & Moderate & & & & & & & & & & & & & & & & & \\
\hline НMT379 & Blood & $\mathrm{B} 2$ & Moderate & & & & & & & & & & & & & & & & & \\
\hline HMT385 & Urine & B2 & Weak & & & & & & & & & & & & & & & & & \\
\hline HMT386 & Urine & $\mathrm{B} 2$ & Strong & & & & & & & & & & & & & & & & & \\
\hline HUB605 & Blood & B2 & Strong & & & & & & & & & & & & & & & & & \\
\hline HMT389 & Urine & $\mathrm{B} 2$ & Weak & & & & & & & & & & & & & & & & & \\
\hline HMT396 & Urine & B2 & Moderate & & & & & & & & & & & & & & & & & \\
\hline HMT399 & Urine & B2 & Moderate & & & & & & & & & & & & & & & & & \\
\hline HUB610 & Blood & B2 & Weak & & & & & & & & & & & & & & & & & \\
\hline HUB647 & Urine & B2 & Strong & & & & & & & & & & & & & & & & & \\
\hline HCB207 & Urine & B2 & Strong & & & & & & & & & & & & & & & & & \\
\hline HCB210 & Blood & B2 & Strong & & & & & & & & & & & & & & & & & \\
\hline НCB214 & Blood & B2 & Strong & & & & & & & & & & & & & & & & & \\
\hline HUB648 & Urine & $\mathrm{B} 2$ & Moderate & & & & & & & & & & & & & & & & & \\
\hline HCB218 & Urine & B2 & Moderate & & & & & & & & & & & & & & & & & \\
\hline HUB649 & Urine & $\mathrm{B} 2$ & Strong & & & & & & & & & & & & & & & & & \\
\hline HUB650 & Urine & B2 & Strong & & & & & & & & & & & & & & & & & \\
\hline HUB652 & Urine & B2 & Strong & & & & & & & & & & & & & & & & & \\
\hline HUB653 & Urine & B2 & Moderate & & & & & & & & & & & & & & & & & \\
\hline HUB655 & Urine & B2 & Strong & & & & & & & & & & & & & & & & & \\
\hline
\end{tabular}


TABLE 3 | (Continued)

\begin{tabular}{|c|c|c|c|c|c|c|c|c|c|c|c|c|c|c|c|c|c|c|c|c|}
\hline \multirow[b]{2}{*}{ 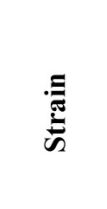 } & \multirow[b]{2}{*}{$\stackrel{5}{0}$} & \multirow[b]{2}{*}{ 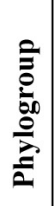 } & \multirow[b]{2}{*}{ 吾 } & \multicolumn{4}{|c|}{ Adhesines } & \multicolumn{5}{|c|}{ Siderophores } & \multicolumn{4}{|c|}{ Toxins } & \multicolumn{4}{|c|}{ ARGs } \\
\hline & & & & $\underset{\Sigma}{\Xi}$ & $\frac{\infty}{n}$ & $\underset{\mathbb{Z}}{\mathbb{Z}}$ & $\begin{array}{l}\mathbb{Z} \\
5 \\
8 \\
8\end{array}$ & 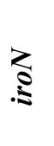 & $\underset{\Xi}{\mathbb{S}}$ & $\widehat{\Xi}$ & S: & 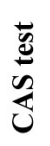 & $\underset{\Sigma}{\Sigma}$ & $\widehat{E}$ & $\underset{\sigma}{\Xi}$ & 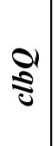 & & 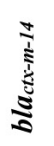 & $\underset{\hbar}{\mathbb{5}}$ & $\underset{\hbar}{\mathfrak{\pi}}$ \\
\hline HUB665 & Urine & B2 & Moderate & & & & & & & & & & & & & & & & & \\
\hline HUB666 & Urine & $\mathrm{B} 2$ & Moderate & & & & & & & & & & & & & & & & & \\
\hline HCB221 & Respiratory & B2 & Moderate & & & & & & & & & & & & & & & & & \\
\hline $\mathrm{HCB} 224$ & Blood & $\mathrm{B} 2$ & Strong & & & & & & & & & & & & & & & & & \\
\hline HCB226 & Blood & B2 & Strong & & & & & & & & & & & & & & & & & \\
\hline HCB227 & Blood & $\mathrm{B} 2$ & Moderate & & & & & & & & & & & & & & & & & \\
\hline HCB231 & Urine & UN & Weak & & & & & & & & & & & & & & & & & \\
\hline $\mathrm{HCB} 232$ & Urine & $\mathrm{B} 2$ & Non producer & & & & & & & & & & & & & & & & & \\
\hline HCB233 & Urine & B2 & Weak & & & & & & & & & & & & & & & & & \\
\hline HMT400 & Urine & B2 & Weak & & & & & & & & & & & & & & & & & \\
\hline НМТ410 & Urine & $\mathrm{B} 2$ & Moderate & & & & & & & & & & & & & & & & & \\
\hline HMT415 & Urine & $\mathrm{B} 2$ & Strong & & & & & & & & & & & & & & & & & \\
\hline HMT418 & Blood & $\mathrm{B} 2$ & Weak & & & & & & & & & & & & & & & & & \\
\hline HMT426 & Urine & B2 & Moderate & & & & & & & & & & & & & & & & & \\
\hline HUB809 & Respiratory & $\mathrm{B} 2$ & Strong & & & & & & & & & & & & & & & & & \\
\hline HUB810 & Respiratory & B2 & Weak & & & & & & & & & & & & & & & & & \\
\hline HCB477 & Urine & B2 & Moderate & & & & & & & & & & & & & & & & & \\
\hline $\mathrm{HCB} 476$ & Respiratory & B2 & Moderate & & & & & & & & & & & & & & & & & \\
\hline HCB475 & Respiratory & B2 & Weak & & & & & & & & & & & & & & & & & \\
\hline HCB473 & Urine & B2 & Weak & & & & & & & & & & & & & & & & & \\
\hline HCB469 & Blood & B2 & Moderate & & & & & & & & & & & & & & & & & \\
\hline HCB463 & Urine & B2 & Strong & & & & & & & & & & & & & & & & & \\
\hline HCB457 & Urine & B2 & Weak & & & & & & & & & & & & & & & & & \\
\hline HCB458 & Blood & B2 & Moderate & & & & & & & & & & & & & & & & & \\
\hline HCB455 & Urine & B2 & Moderate & & & & & & & & & & & & & & & & & \\
\hline
\end{tabular}

Colored squares denote the presence of the gene or positivity of the test.

ARGs: antimicrobial resistance genes. UN: Unknown.

found similar percentages of fully susceptible strains but a higher rate of MDR in the collection under study. They also reported the highest average resistance percentage for aminopenicillins (58.7\%), followed by fluoroquinolones (25.7\%). These differences could be probably due to most of the strains in the present study were isolated from urine, and some of the most common antibiotics prescribed in UTIs are ciprofloxacin and trimethoprim-sulfamethoxazole. Previous studies conducted by our group showed no statistically significant relationship between biofilm formation ability and ciprofloxacin resistance among E. coli strains, but this association was found in Pseudomonas aeruginosa (Cepas et al., 2019). However, after analyzing whether this association existed in our study, a statistically significant association was found between non-biofilm-forming strains and resistance to ciprofloxacin. These variations among the data could be due to the greater number of strains analyzed in the present research. Several studies reported that quinoloneresistant strains were less virulent than quinolone-susceptible strains, observing that fimbriae genes, associated with biofilm formation, were less prevalent among nalidixic acid-resistant E. coli isolates (Vila et al., 2002; Horcajada et al., 2005). Moreover, the study by Fàbrega et al. (2014) showed that the acquisition of quinolone resistance was related to a decrease in biofilm formation in Salmonella enterica strains (Fàbrega et al., 2014) which may explain our results.

Regarding ESBL, these were highly prevalent in our study (19.4\%) compared to the study conducted by Flament-Simon et al. (2020) in which only 13 of the strains (6.6\%) isolated in Spain and France in 2016 produced ESBL enzymes (FlamentSimon et al., 2020). In agreement with our results, several epidemiological studies confirm that $b l_{C T X-M-15}$ is one the most common ESBL among clinical isolates from Spain. However, bla $a_{C T X-M-14}$ and $b l a_{C T X-M-27}$ have also been found in this country (Dahbi et al., 2014; Merino et al., 2016, 2018). Interestingly, three strains carrying bla $C T X-M-28$ were found in our study, which is less prevalent than other bla $a_{C T X-M-1}$ enzymes (Livermore et al., 2007). When we analyzed the relation between biofilm formation and ESBL production, we did not find any correlation between these two variables. However, Shrestha et al. (2019) found a positive correlation between these two features (Shrestha et al., 2019). The differences between the two studies could be due to the higher percentage of beta-lactamases (50.9\% vs. $19.4 \%$ ) they 


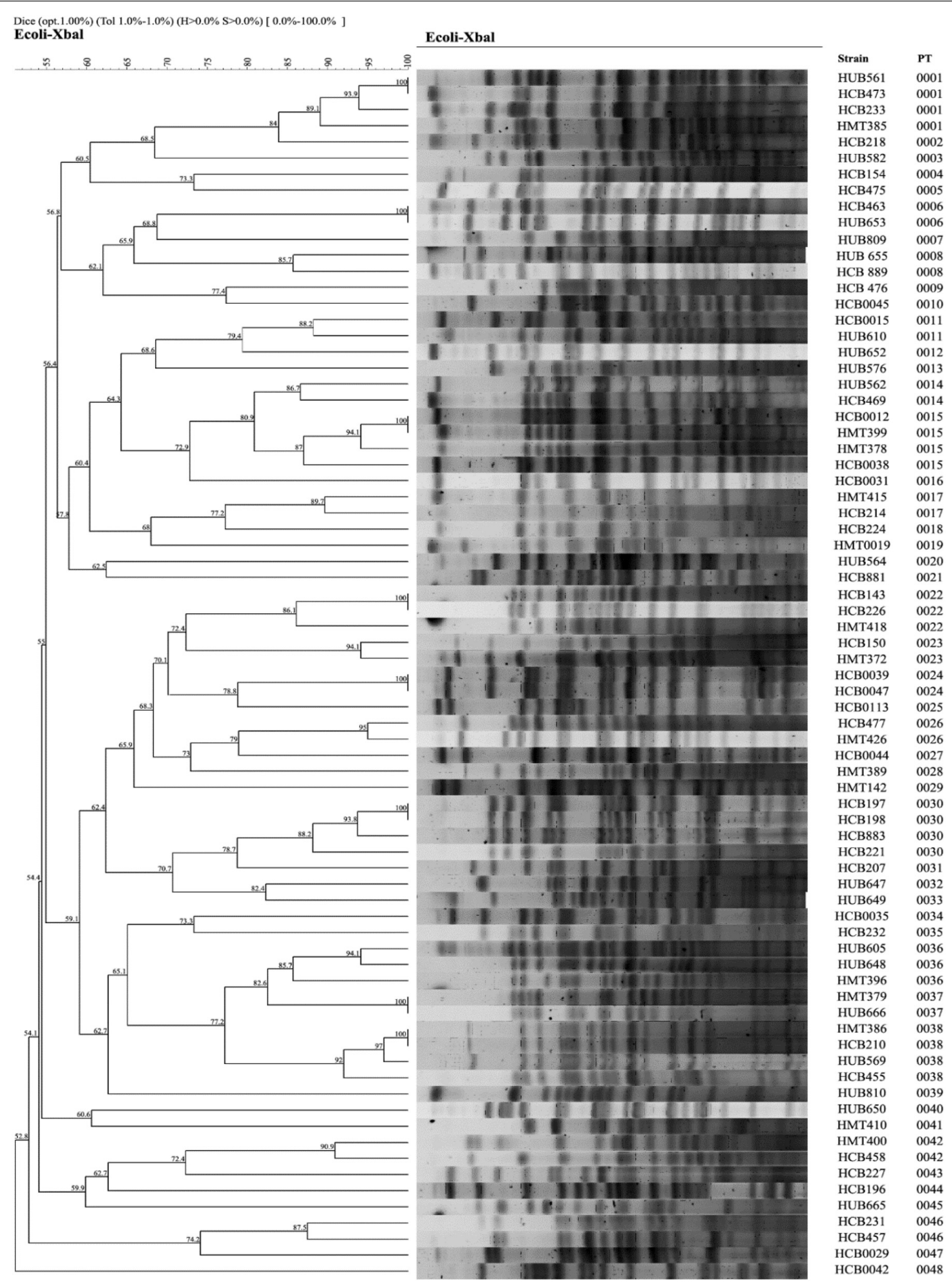

FIGURE 7 | Clonal relationship analysis of the colibactin strains assessed by PFGE using Xbal. PT: Pulsotype.

found. These results showing a worrying situation, since having a high percentage of ESBL among biofilm-forming strains makes very difficult their eradication.

As for virulence, we found 14 (3.7\%) strains carrying all the VFGs tested. However, most were associated with low antimicrobial resistance rates. We observed a statistically significant correlation between the presence of different siderophores, adhesins or toxins and the ability to form biofilms. Siderophores are small molecules with high affinity for iron (Holden and Bachman, 2015). They are considered an important virulence factor in most Gram-negative bacteria. In S. maltophilia, iron plays a significant role in biofilm formation 
and production of EPS (Kalidasan et al., 2018). In P. aeruginosa, siderophore-deficient clones showed reduced biofilm formation ability (Banin et al., 2005). In E. coli, studies by May and Okabe (2011) have shown that biofilm formation is favored in media with low iron concentrations (May and Okabe, 2011). In support of previous studies, we found a significant correlation between the presence of siderophore-encoding genes, such as iroN, and the ability to form biofilms. In addition, resistant strains produced more siderophores than their susceptible counterparts. Recently, it has been reported that the introduction of the mobile genetic element ICEKp from Klebsiella pneumoniae or a plasmid encoding YbtPQ (a siderophore importer encoded in the yersiniabactin cluster) reduced the susceptibility of E. coli to a wide range of antimicrobials (Farzand et al., 2021). Regarding adhesins, type 1 fimbriae are the best known adhesive organelles among Enterobacteriaceae (Abdelhalim et al., 2020) playing an important role in the initial steps of biofilm formation. As expected, we found a significant association between the presence of the fimH gene and biofilm formation. The adhesins sfa and $p a p A$ also showed a significant association with biofilm formation. Although poly- $\beta$-1,6-N-acetyl-D-glucosamine polymer is associated with biofilm formation by mediating cell-to-cell adhesion and attachment to surfaces (Sharma et al., 2016), our results showed no statistical correlation between the presence of the pgaA gene and the capacity to form biofilms.

An important finding of the present work is the high presence of the toxin colibactin among the strains under study. Colibactin is a virulence determinant and a genotoxic enzyme synthesized by polyketide synthases and encoded by a 54-kb genomic island designated pks (Faïs et al., 2018). Colibactin may induce DNA damage in the host and has been correlated with colorectal cancer in humans (Wernke et al., 2020). Previous studies have confirmed the presence of $p k s$-positive strains among ExPEC (Auvray et al., 2021). Interestingly, 75 of our isolates (19.9\%) were colibactin-encoding strains, a higher percentage than this observed by Suresh et al. (2018). Analysis of the association between colibactin and other VFGs showed a significant correlation of this toxin with the siderophoreencoding genes iroN and irpl; the adhesin-encoding genes $p a p A$, fimH, pgaA, and sfa; and the toxin genes $c n f-1$ and $h l y A$. Iron is an essential element for the survival of $E$. coli. Previous studies confirm that the $p k s$ island is involved in the synthesis of siderophores such as yersiniabactin, enterobactin, and salmochelins via phosphopantetheinyl transferase ClbA (Martin et al., 2013). In addition, it has been suggested that E. coli strains carrying hemolysin and colibactin have advantages in colorectal colonization and subsequent cancer (Yoshikawa et al., 2020). As in our case, it has been previously reported that phylogenetic group B2 is predominant among colibactinencoding E. coli strains (Sarshar et al., 2017). However, the high clonal diversity of PFGE analysis among colibactinpositive E. coli isolates studied suggests that colibactin may be distributed in a wide variety of strains and clones. Worryingly, Putze et al. (2009) detected colibactin-related genes associated with an ICE-like element in several enterobacteria, not only in E. coli, paving the way for the spread of this gene cluster among species (Putze et al., 2009). Furthermore, we observed low rates of resistance to antimicrobial agents among colibactin-positive isolates, which is consistent with previous studies (Sarshar et al., 2017; Morgan et al., 2019). Although colibactin-encoding genes may have a direct influence on other biosynthetic pathways, our findings support the hypothesis that the presence of colibactin-encoding genes may be related to biofilm formation. In this sense, several studies showed a high capacity for biofilm formation among the pks-carrying strains studied (Raisch et al., 2014; Suresh et al., 2018). Likewise, Dejea et al. (2014) conducted a study in two geographically distinct cohorts from the United States and Malaysia finding that $89 \%$ of cases of right-sided colorectal tumors presented biofilms in the biopsies samples, concluding that a significant association between the presence of biofilms and colorectal cancer exists (Dejea et al., 2014). In another study of patients with familial adenomatous polyposis, the bacterial biofilms found were composed predominantly by $E$. coli and Bacteroides fragilis. Genes encoding colibactin $(c l b B)$ were found at high levels in strains from these patients compared to strains isolated from healthy individuals (Dejea et al., 2018). Additionally, uropathogenic E. coli strains carrying the $p k s$ island have also been described. Chagneau et al. (2021) detected colibactin in $24.7 \%$ of urine samples from patients with community-acquired pyelonephritis, cystitis or asymptomatic bacteriuria (Chagneau et al., 2021). They also reported that colibactin was produced during UTIs and induced DNA damage in urothelial cells (Chagneau et al., 2021). Similarly, the study conducted by Morgan and collaborators in an in vivo model of ascending UTI in rats, showed that isolates carrying the $c n f-1, c l b A$ and $c l b Q$ genes induced severe UTIs within 48-72 h (Morgan et al., 2019). Thus, strains carrying colibactin-encoding genes can produce biofilms and cause severe disease not only in the intestine but also in the urinary tract, and probably in other less studied anatomic sites.

\section{CONCLUSION}

Ciprofloxacin resistance was associated with lower biofilm production ability among the E. coli strains under study. Furthermore, biofilm formation ability was correlated with the presence of some siderophores, adhesins, and toxins. The high percentage of strains harboring the colibactin-encoding genes and the significant correlation between this toxin and biofilm formation, suggest that colibactin could be a promising therapeutic target to prevent biofilm formation. Nevertheless, further studies are needed to confirm our hypothesis and to better understand the impact of colibactin production on human health.

\section{DATA AVAILABILITY STATEMENT}

The original contributions presented in the study are included in the article/supplementary material, further inquiries can be directed to the corresponding author. 


\section{AUTHOR CONTRIBUTIONS}

SS and VB: conceptualization and writing-original draft preparation. VB, YG, CR, and MS: methodology. VB: statistical analysis. VB, CR, and SS: writing - review and editing. All authors have read and agreed to the published version of the manuscript.

\section{FUNDING}

This work was funded by Planes Nacionales de I + D + iI20082011/2013-2016 and Instituto de Salud Carlos III (PI19/00478),

\section{REFERENCES}

Abdelhalim, K. A., Uzel, A., and Unal, N. G. (2020). The role of major virulence factors and pathogenicity of adherent-invasive Escherichia coli in patients with Crohn's disease. Prz. Gastroenterol. 15, 279-288. doi: 10.5114/pg.2020.93235

Auvray, F., Perrat, A., Arimizu, Y., Chagneau, C. V., Bossuet-Greif, N., Massip, C., et al. (2021). Insights into the acquisition of the pks island and production of colibactin in the Escherichia coli population. Microb. Genomics 7:579. doi: 10.1099/mgen.0.000579

Banin, E., Vasil, M. L., and Greenberg, E. P. (2005). Iron and Pseudomonas aeruginosa biofilm formation. Proc. Natl. Acad. Sci. USA 102, 11076-11081. doi: 10.1073/pnas.0504266102

Beloin, C., Roux, A., and Ghigo, J.-M. (2008). Escherichia coli biofilms. Curr. Top. Microbiol. Immunol. 322, 249-289. doi: 10.1007/978-3-540-75418-3_12

Beloin, C., Valle, J., Latour-Lambert, P., Faure, P., Kzreminski, M., Balestrino, D., et al. (2004). Global impact of mature biofilm lifestyle on Escherichia coli K-12 gene expression. Mol. Microbiol. 51, 659-674. doi: 10.1046/j.1365-2958.2003. 03865.x

Blount, Z. D. (2015). The unexhausted potential of E. coli. Elife 4, 1-12. doi: 10.7554/eLife.05826

Cantón, R., Loza, E., Arcay, R. M., Cercenado, E., Castillo, F. J., Cisterna, R., et al. (2021). Antimicrobial activity of ceftolozane-tazobactam against Enterobacterales and Pseudomonas aeruginosa recovered during the Study for Monitoring Antimicrobial Resistance Trends (SMART) program in Spain (2016-2018). Rev. Esp. Quimioter. 34, 228-237. doi: 10.37201/req/019.2021

Cepas, V., Ballén, V., Gabasa, Y., Ramírez, M., López, Y., and Soto, S. M. (2020). Transposon insertion in the purL gene induces biofilm depletion in Escherichia coli ATCC 25922. Pathogens 9, 1-22. doi: 10.3390/pathogens 9090774

Cepas, V., López, Y., Muñoz, E., Rolo, D., Ardanuy, C., Martí, S., et al. (2019). Relationship between biofilm formation and antimicrobial resistance in Gramnegative bacteria. Microb. Drug Resist. 25, 72-79. doi: 10.1089/mdr.2018.0027

Chagneau, C. V., Massip, C., Bossuet-Greif, N., Fremez, C., Motta, J. P., Shima, A., et al. (2021). Uropathogenic E. coli induces DNA damage in the bladder. PLoS Pathog. 17:1-18. doi: 10.1371/JOURNAL.PPAT.1009310

Clermont, O., Christenson, J. K., Denamur, E., and Gordon, D. M. (2013). The Clermont Escherichia coli phylo-typing method revisited: improvement of specificity and detection of new phylo-groups. Environ. Microbiol. Rep. 5, 58-65. doi: 10.1111/1758-2229.12019

CLSI (2020). CLSI. Performance Standards for Antimicrobial Susceptibility Testing, 30th Edition. CLSI Supplement M100. Wayne, PA: Clinical and Laboratory Standard Institute.

Dahbi, G., Mora, A., Mamani, R., Lopez, C., Alonso, M. P., Marzoa, J., et al. (2014). Molecular epidemiology and virulence of Escherichia coli O16: H5ST131: Comparison with $\mathrm{H} 30$ and H30-Rx subclones of O25b: H4-ST131. Int. J. Med. Microbiol. 304, 1247-1257. doi: 10.1016/j.ijmm.2014.10.002

Dejea, C., Fathi, P., Craig, J. M., Boleij, A., Taddese, R., Geis, A. L., et al. (2018). Patients with familial adenomatous polyposis harbor colonic biofilms containing tumorigenic bacteria. Science 359, 592-597. doi: 10.1126/science. aah3648.Patients

Dejea, C. M., Wick, E. C., Hechenbleikner, E. M., White, J. R., Mark Welch, J. L., Rossettid, B. J., et al. (2014). Microbiota organization is a distinct feature of proximal colorectal cancers. Proc. Natl. Acad. Sci. USA 111, 18321-18326. doi: 10.1073/pnas.1406199111
Subdirección General de Redes y Centros de Investigación Cooperativa, Ministerio de Economía y Competitividad, Spanish Network for Research in Infectious Diseases (REIPI RD12/0015/0013 and REIPI RD16/0016/0010) cofinanced by European Development Regional Fund "A way to achieve Europe" and operative program Intelligent Growth 2014-2020. ISGlobal was a CERCA center from the Generalitat of Catalunya and a Severo Ochoa Center (Spanish Ministry of Science, Innovations, and Universities). VB has a grant from Ministerio de Ciencia, Tecnología e Innovación (Colombia).

Dubois, D., Delmas, J., Cady, A., Robin, F., Sivignon, A., Oswald, E., et al. (2010). Cyclomodulins in urosepsis strains of Escherichia coli. J. Clin. Microbiol. 48, 2122-2129. doi: 10.1128/JCM.02365-09

Durmaz, R., Otlu, B., Koksal, F., Hosoglu, S., Ozturk, R., Ersoy, Y., et al. (2009). The optimization of a rapid pulsed-field gel electrophoresis protocol for the typing of Acinetobacter baumannii, Escherichia coli and Klebsiella spp. Jpn. J. Infect. Dis. 62, 372-377.

Dziubańska-Kusibab, P. J., Berger, H., Battistini, F., Bouwman, B. A. M., Iftekhar, A., Katainen, R., et al. (2020). Colibactin DNA-damage signature indicates mutational impact in colorectal cancer. Nat. Med. 26, 1063-1069. doi: 10.1038/ s41591-020-0908-2

European Centre for Disease Prevention and Control (ECDC) (2017). Antimicrobial resistance surveillance in Europe 2016. Annual Report of the European Antimicrobial Resistance Surveillance Network (EARS-Net). Solna Municipality: ECDC.

Fàbrega, A., Soto, S. M., Ballesté-Delpierre, C., Fernández-Orth, D., Jiménez de Anta, M. T., and Vila, J. (2014). Impact of quinolone-resistance acquisition on biofilm production and fitness in Salmonella enterica. J. Antimicrob. Chemother. 69, 1815-1824. doi: 10.1093/jac/dku078

Faïs, T., Delmas, J., Barnich, N., Bonnet, R., and Dalmasso, G. (2018). Colibactin: More than a new bacterial toxin. Toxins 10, 16-18. doi: 10.3390/toxins100 40151

Farzand, R., Rajakumar, K., Barer, M. R., Freestone, P. P. E., Mukamolova, G. V., Oggioni, M. R., et al. (2021). A virulence associated siderophore importer reduces antimicrobial susceptibility of Klebsiella pneumoniae. Front. Microbiol. 12:1-9. doi: 10.3389/fmicb.2021.607512

Flament-Simon, S. C., Nicolas-Chanoine, M. H., García, V., Duprilot, M., Mayer, N., Alonso, M. P., et al. (2020). Clonal structure, virulence factor-encoding genes and antibiotic resistance of Escherichia coli, causing urinary tract infections and other extraintestinal infections in humans in spain and france during 2016. Antibiotics 9, 1-17. doi: 10.3390/antibiotics9040161

Friedlander, R. S., Vogel, N., and Aizenberg, J. (2015). Role of flagella in adhesion of Escherichia coli to abiotic surfaces. Langmuir 31, 6137-6144. doi: 10.1021/ acs.langmuir.5b00815

Guerra, B., Junker, E., Miko, A., Helmuth, R., and Mendoza, M. C. (2004). Characterization and localization of drug resistance determinants in multidrugresistant, integron-carrying Salmonella enterica Serotype Typhimurium strains. Microb. Drug Resist. 10, 83-91.

Guerrieri, C. G., Pereira, M. F., Galdino, A. C. M., Dos Santos, A. L. S., Elias, W. P., Schuenck, R. P., et al. (2019). Typical and atypical enteroaggregative Escherichia coli are both virulent in the Galleria mellonella model. Front. Microbiol. 10:1791. doi: 10.3389/fmicb.2019.01791

Guttenplan, S. B., and Kearns, D. B. (2013). Regulation of flagellar motility during biofilm formation. FEMS Microbiol. Rev. 37, 849-871. doi: 10.1111/1574-6976. 12018

Holden, V. I., and Bachman, M. A. (2015). Diverging roles of bacterial siderophores during infection. Metallomics 7, 986-995. doi: 10.1039/c4mt0 $0333 \mathrm{k}$

Horcajada, J. P., Soto, S., Gajewski, A., Smithson, A., Jiménez De Anta, M. T., Mensa, J., et al. (2005). Quinolone-resistant uropathogenic Escherichia coli strains from phylogenetic group B2 have fewer virulence factors than their susceptible counterparts. J. Clin. Microbiol. 43, 2962-2964. doi: 10.1128/JCM. 43.6.2962-2964.2005 
Houdouin, V., Bonacorsi, S., Bidet, P., Bingen-Bidois, M., Barraud, D., and Bingen, E. (2006). Phylogenetic background and carriage of pathogenicity island-like domains in relation to antibiotic resistance profiles among Escherichia coli urosepsis isolates. J. Antimicrob. Chemother. 58, 748-751. doi: 10.1093/jac/ dkl326

Johnson, J. R., and Stell, A. L. (2000). Extended virulence genotypes of Escherichia coli strains from patients with urosepsis in relation to phylogeny and host compromise. J. Infect. Dis. 181, 261-272. doi: 10.1086/315217

Johnson, J. R., Johnston, B., Kuskowski, M. A., Nougayrede, J. P., and Oswald, E. (2008). Molecular epidemiology and phylogenetic distribution of the Escherichia coli pks genomic island. J. Clin. Microbiol. 46, 3906-3911. doi: 10. 1128/JCM.00949-08

Johnson, J. R., Russo, T. A., Tarr, P. I., Carlino, U., Bilge, S. S., Vary, J. C., et al. (2000). Molecular epidemiological and phylogenetic associations of two novel putative virulence genes, iha and $i r o N_{E}$. coli, among Escherichia coli isolates from patients with urosepsis. Infect. Immun. 68, 3040-3047. doi: 10.1128/IAI.68.5. 3040-3047.2000

Kalidasan, V., Joseph, N., Kumar, S., Awang Hamat, R., and Neela, V. K. (2018). Iron and virulence in Stenotrophomonas maltophilia: All We Know So Far. Front. Cell Infect. Microbiol. 8:401. doi: 10.3389/fcimb.2018. 00401

Leflon-Guibout, V., Jurand, C., Bonacorsi, S., Espinasse, F., Guelfi, M. C., Duportail, F., et al. (2004). Emergence and spread, of three clonally related virulent isolates of CTX-M-15-producing Escherichia coli with variable resistance to aminoglycosides and tetracycline in a French geriatric hospital. Antimicrob. Agents Chemother. 48, 3736-3742. doi: 10.1128/AAC.48.10.37363742.2004

Lescat, M., Poirel, L., and Nordmann, P. (2018). Rapid multiplex polymerase chain reaction for detection of $m c r-1$ to $m c r-5$ genes. Diagn. Microbiol. Infect. Dis. 92, 267-269. doi: 10.1016/j.diagmicrobio.2018.04.010

Livermore, D. M., Canton, R., Gniadkowski, M., Nordmann, P., Rossolini, G. M., Arlet, G., et al. (2007). CTX-M: Changing the face of ESBLs in Europe. J. Antimicrob. Chemother. 59, 165-174. doi: 10.1093/jac/dkl483

Magiorakos, A. P., Srinivasan, A., Carey, R. B., Carmeli, Y., Falagas, M. E., Giske, C. G., et al. (2012). Multidrug-resistant, extensively drug-resistant and pandrug-resistant bacteria: An international expert proposal for interim standard definitions for acquired resistance. Clin. Microbiol. Infect. 18, 268-281. doi: 10.1111/j.1469-0691.2011.03570.x

Manges, A. R., Geum, H. M., Guo, A., Edens, T. J., Fibke, C. D., and Pitout, J. D. D. (2019). Global extraintestinal pathogenic Escherichia coli (ExPEC) lineages. Clin. Microbiol. Rev. 32, 1-25.

Martin, P., Marcq, I., Magistro, G., Penary, M., Garcie, C., Payros, D., et al. (2013). Interplay between siderophores and colibactin genotoxin biosynthetic pathways in Escherichia coli. PLoS Pathog. 9:3437. doi: 10.1371/JOURNAL.PPAT. 1003437

May, T., and Okabe, S. (2011). Enterobactin is required for biofilm development in reduced-genome Escherichia coli. Environ. Microbiol. 13, 3149-3162. doi: 10.1111/j.1462-2920.2011.02607.x

Merino, I., Hernández-García, M., Turrientes, M. C., Pérez-Viso, B., López-Fresneña, N., Diaz-Agero, C., et al. (2018). Emergence of ESBLproducing Escherichia coli ST131-C1-M27 clade colonizing patients in Europe. J. Antimicrob. Chemother. 73, 2973-2980. doi: 10.1093/jac/ dky296

Merino, I., Shaw, E., Horcajada, J. P., Cercenado, E., Mirelis, B., Pallarés, M. A., et al. (2016). CTX-M-15-H30Rx-ST131 subclone is one of the main causes of healthcare-associated ESBL-producing Escherichia coli bacteraemia of urinary origin in Spain. J. Antimicrob. Chemother. 71, 2125-2130. doi: 10.1093/jac/ dkw133

Monstein, H. J., Ostholm-Balkhed, A., Nilsson, M. V., Nilsson, M., Dornbusch, K., and Nilsson, L. E. (2007). Multiplex PCR amplification assay for the detection of bla $a_{S H V}, b l a_{T E M}$ and bla $a_{C T X-M}$ genes in Enterobacteriaceae. Apmis 115, 1400-1408. doi: 10.1111/j.1600-0463.2007.00722.x

Morgan, R. N., Saleh, S. E., Farrag, H. A., and Aboulwafa, M. M. (2019). Prevalence and pathologic effects of colibactin and cytotoxic necrotizing factor-1 (Cnf 1) in Escherichia coli: Experimental and bioinformatics analyses. Gut. Pathog. 11, 1-18. doi: 10.1186/s13099-019-0304-y

Pai, H., Choi, E. H., Lee, H. J., JungYun, H., and Jacoby, G. A. (2001). Identification of CTX-M-14 extended-spectrum $\beta$-lactamase in clinical isolates of Shigella sonnei. Escherichia coli, and Klebsiella pneumoniae in Korea. J. Clin. Microbiol. 39, 3747-3749. doi: 10.1128/JCM.39.10.3747-3749.2001

Park, C. H., Robicsek, A., Jacoby, G. A., Sahm, D., and Hooper, D. C. (2006). Prevalence in the United States of $a a c\left(6^{\prime}\right)-I b-c r$ encoding a ciprofloxacinmodifying enzyme. Antimicrob. Agents Chemother. 50, 3953-3955. doi: 10. 1128/AAC.00915-06

Putze, J., Hennequin, C., Nougayrède, J. P., Zhang, W., Homburg, S., Karch, H., et al. (2009). Genetic structure and distribution of the colibactin genomic island among members of the family Enterobacteriaceae. Infect. Immun. 77, 4696-4703.

Raisch, J., Buc, E., Bonnet, M., Sauvanet, P., Vazeille, E., de Vallée, A., et al. (2014). Colon cancer-associated B2 Escherichia coli colonize gut mucosa and promote cell proliferation. World J. Gastroenterol. 20, 6560-6572. doi: 10.3748/wjg.v20. i21.6560

Robicsek, A., Strahilevitz, J., Jacoby, G. A., Macielag, M., Abbanat, D., Chi, H. P., et al. (2006). Fluoroquinolone-modifying enzyme: a new adaptation of a common aminoglycoside acetyltransferase. Nat. Med. 12, 83-88. doi: 10.1038/ $\mathrm{nm} 1347$

Sáez-López, E., Bosch, J., Salvia, M. D., Fernández-Orth, D., Cepas, V., FerrerNavarro, M., et al. (2017). Outbreak caused by Escherichia coli O18:K1:H7 sequence type 95 in a neonatal intensive care unit in Barcelona, Spain. Pediatr. Infect. Dis. J. 36, 1079-1086. doi: 10.1097/INF.0000000000001652

Sarowska, J., Futoma-Koloch, B., Jama-Kmiecik, A., Frej-Madrzak, M., Ksiazczyk, M., Bugla-Ploskonska, G., et al. (2019). Virulence factors, prevalence and potential transmission of extraintestinal pathogenic Escherichia coli isolated from different sources: Recent reports. Gut. Pathog. 11, 1-16. doi: 10.1186/ s13099-019-0290-0

Sarshar, M., Scribano, D., Marazzato, M., Ambrosi, C., Aprea, M. R., Aleandri, M., et al. (2017). Genetic diversity, phylogroup distribution and virulence gene profile of pks positive Escherichia coli colonizing human intestinal polyps. Microb. Pathog. 112, 274-278. doi: 10.1016/j.micpath.2017.10.009

Schwyn, B., and Neilands, J. B. (1987). Universal chemical assay for the detection and determination of siderophores. Anal. Biochem. 160, 47-56. doi: 10.1016/ 0003-2697(87)90612-9

Sharma, G., Sharma, S., Sharma, P., Chandola, D., Dang, S., Gupta, S., et al. (2016). Escherichia coli biofilm: development and therapeutic strategies. J. Appl. Microbiol. 121, 309-319. doi: 10.1111/jam.13078

Shrestha, R., Khanal, S., Poudel, P., Khadayat, K., Ghaju, S., Bhandari, A., et al. (2019). Extended spectrum $\beta$-lactamase producing uropathogenic Escherichia coli and the correlation of biofilm with antibiotics resistance in Nepal. Ann. Clin. Microbiol. Antimicrob. 18, 1-6. doi: 10.1186/s12941-019-0340-y

Smith, D. R., Price, J. E., Burby, P. E., Blanco, L. P., Chamberlain, J., and Chapman, M. R. (2017). The production of curli amyloid fibers is deeply integrated into the biology of Escherichia coli. Biomolecules 7:75. doi: 10.3390/biom70 40075

Stepanović, S., Vuković, D., Hola, V., Di Bonaventura, G., Djukić, S., Ćirković, I., et al. (2007). Quantification of biofilm in microtiter plates: Overview of testing conditions and practical recommendations for assessment of biofilm production by staphylococci. Apmis 115, 891-899. doi: 10.1111/j.1600-0463. 2007.apm_630.x

Suresh, A., Ranjan, A., Jadhav, S., Hussain, A., Shaik, S., Alam, M., et al. (2018). Molecular genetic and functional analysis of pks-harboring, extra-intestinal pathogenic Escherichia coli from India. Front. Microbiol. 9:1-8. doi: 10.3389/ fmicb.2018.02631

Takahashi, A., Kanamaru, S., Kurazono, H., Kunishima, Y., Tsukamoto, T., Ogawa, O., et al. (2006). Escherichia coli isolates associated with uncomplicated and complicated cystitis and asymptomatic bacteriuria possess similar phylogenies, virulence genes, and O-serogroup profiles. J. Clin. Microbiol. 44, 4589-4592. doi: 10.1128/JCM.02070-06

Van Gerven, N., Van der Verren, S. E., Reiter, D. M., and Remaut, H. (2018). The role of functional amyloids in bacterial virulence. J. Mol. Biol. 430, 3657-3684. doi: 10.1016/j.jmb.2018.07.010

Vila, J., Simon, K., Ruiz, J., Horcajada, J. P., Velasco, M., Barranco, M., et al. (2002). Are quinolone-resistant uropathogenic Escherichia coli less virulent? J. Infect. Dis. 186, 1039-1042.

Wernke, K. M., Xue, M., Tirla, A., Kim, C. S., Crawford, J. M., and Herzon, S. B. (2020). Structure and bioactivity of colibactin. Bioorganic Med. Chem. Lett. 30:127280. doi: $10.1016 /$ j.bmcl.2020.127280 
Wiegand, I., Geiss, H. K., Mack, D., Stu, E., Seifert, H., and Icrobiol, J. C. L. I. N. M. (2007). Detection of Extended-Spectrum Beta-Lactamases among Enterobacteriaceae by use of semiautomated microbiology systems and manual detection procedures. J. Clin. Microbiol. 45, 1167-1174. doi: 10.1128/ JCM.01988-06

Woodford, N., Fagan, E. J., and Ellington, M. J. (2006). Multiplex PCR for rapid detection of genes encoding CTX-M extended-spectrum $\beta$-lactamases [4]. J. Antimicrob. Chemother. 57, 154-155. doi: 10.1093/jac/dki412

Xu, J. G., Cheng, B., Wen, X., Cui, S., and Ye, C. (2000). High-pathogenicity island of Yersinia spp. in Escherichia coli strains isolated from diarrhea patients in China. J. Clin. Microbiol. 38, 4672-4675. doi: 10.1128/jcm.38.12.4672-4675. 2000

Yoshikawa, Y., Tsunematsu, Y., Matsuzaki, N., Hirayama, Y., Higashiguchi, F., Sato, M., et al. (2020). Characterization of colibactin-producing Escherichia coli isolated from Japanese patients with colorectal cancer. Japanese J. Infect. Dis. 73, 437-442.
Conflict of Interest: The authors declare that the research was conducted in the absence of any commercial or financial relationships that could be construed as a potential conflict of interest.

Publisher's Note: All claims expressed in this article are solely those of the authors and do not necessarily represent those of their affiliated organizations, or those of the publisher, the editors and the reviewers. Any product that may be evaluated in this article, or claim that may be made by its manufacturer, is not guaranteed or endorsed by the publisher.

Copyright $\odot 2022$ Ballén, Gabasa, Ratia, Sánchez and Soto. This is an open-access article distributed under the terms of the Creative Commons Attribution License (CC BY). The use, distribution or reproduction in other forums is permitted, provided the original author(s) and the copyright owner(s) are credited and that the original publication in this journal is cited, in accordance with accepted academic practice. No use, distribution or reproduction is permitted which does not comply with these terms. 